\title{
Cost-effectiveness analysis for priority-setting in South Africa - what are the possibilities?
}

\author{
Jane Doherty
}

Priority-setting in the health system is necessary because resources are constrained. The role of cost-effectiveness analysis in supporting decision-making around health care priorities in South Africa is explored by referring to South African studies that have provided clinical and policy guidance at the levels of the patient, the service and the population. Cost-effectiveness evidence is positioned in relation to other concerns such as equity and the overall performance of the health system.

S Afr Med J 2010; 100: 816-821.
Cost-effectiveness analysis (CEA) is taken to mean comparing the costs of different interventions against each 'unit of gain' (such as a life saved or disability averted) - it identifies which intervention provides the 'best value for money'. A key assumption is that, if employed in South Africa, CEA should support the achievement of equity and strengthen the district health system. Some examples are provided in the main text; a complete list appears in Appendix A.

\section{Setting priorities at the level of the patient}

At the level of the patient, CEA helps to decide which of several alternative interventions is the most cost-effective in addressing a specific problem. A study in KwaZulu-Natal found that replacing monotherapy for malaria with dual therapy led to a decline in outpatient cases and inpatient admissions by a third and half, respectively. ${ }^{1}$ Although dual therapy was considerably more expensive, its better cure rate led to large savings. CEA is also used to distinguish which patients with a specific condition will benefit most from a specific intervention. A Cape Town study concluded that initiating highly active antiretroviral therapy (ART) before a patient's CD4 count falls to $200 / \mu \mathrm{l}$ is more cost-effective: early therapy provides significant clinical benefits, even though the total cost of treatment is less when it commences below a CD4 count of $200 .{ }^{2}$ CEA can therefore encourage funders to invest in interventions that appear more costly (per patient treated) but lead to an overall reduction in the demands on the health service.

As knowledge around the cost-effectiveness of interventions accumulates, it becomes incorporated into treatment protocols that guide clinicians in their practice. Treatment protocols are commonly used in the South African public sector and are reinforced by the Essential Drugs List, which constrains the options for treatment. In the private sector, treatment protocols also determine reimbursement patterns and authorisation for treatment for patients belonging to medical schemes.

CEA therefore moves beyond affecting decisions around the different care options for an individual patient to influence the treatment patterns of providers. This can enhance the equity and efficiency of the health system. A Mozambican study investigated the use of rapid diagnostic tests that are performed on people showing

School of Public Health, University of the Witwatersrand, Johannesburg Jane Doherty, BVSc, MPhil, DHSM clinical signs of malaria to determine whether they are carrying the parasite. The test saves costs, as expensive antimalarial drugs (specifically artemisinin-based combination therapies) are only given to those suffering from the disease. However, the test itself costs money. The study found that it would be even more cost-saving to limit rapid diagnostic testing to patients older than 6 years and to treat all patients under 6 years old simply on the basis of clinical diagnosis. As children under 6 experience the most severe malaria, the authors felt that health care providers would, in any case, find it difficult to deny treatment to children who tested negative. ${ }^{3}$

CEA studies challenged South African hypertension treatment guidelines on the basis that, if applied uniformly to all patients, they would lead to some cost-ineffective treatment decisions, poorer health outcomes and wasted resources. ${ }^{4-5}$ It was found that the costeffectiveness of South African hypertension treatment guidelines is poor because the decision to treat is based only on a blood pressure above a target level. The flaw in this approach is that the combined impact of several risk factors is not taken into account (the 'global' risk): some people may fall above the blood pressure target but have a low global risk, while others may fall below the target and have a high global risk. The guidelines therefore lead to over-treatment of lowrisk people and under-treatment of high-risk people. Using a global risk approach would save considerable resources and improve health outcomes, demonstrating the value of including CEA in protocols that are based purely on epidemiological and effectiveness data.

\section{Setting priorities at the level of the service}

CEAs can adjudicate between different modes of service delivery. A study on the outcomes and costs of tuberculosis (TB) treatment in Cape Town compared clinic-based care and observation with clinicbased care supported by observation in the community by community health workers. The study included the costs faced by patients, rather than simply those incurred by the health service, and found that using community health workers improved the affordability and cost-effectiveness of treatment. ${ }^{6}$ This led directly to a national policy on the remuneration of community health workers. ${ }^{7}$ Such studies promote improved efficiency and contribute to equity by improving access and reducing the financial burden of care on households.

Another study found that the 'ProTEST package' of combined TB and HIV interventions in the primary care setting in Cape Town saved costs. ${ }^{8}$ Preventing TB cost less than previous estimates because of the linkage of prevention and care interventions for both TB and HIV, showing the potential of CEA in encouraging the integration of services.

Achieving efficiency at the service level is of particular concern for the more expensive care provided by specialists at regional and 
central hospitals. In South Africa the development of CEA capacity to inform the use of expensive procedures, technologies and medicines is being debated. ${ }^{9-11}$ CEA could eliminate cost-ineffective diagnostic and therapeutic approaches and target rationed services towards patients most able to benefit from them. It could also suggest a shift in the configuration of services, promoting care at lower levels of the health system. An important finding of the second Disease Control Priorities for Developing Countries Project was that emergency (and even some elective) surgery and the resuscitation of newborns can be highly cost-effective and affordable when rendered at the district and even the community level. However, this depends on the use of midlevel workers and simple technologies that would make such services more accessible than previously considered feasible. ${ }^{12-13}$

\section{Setting priorities at the level of the population}

Priority-setting at population level decides the relative importance of different health problems and whether - and how - they should be addressed. One instance of how CEA can assist is to identify interventions that need to be introduced to respond to emerging conditions. Often this process begins with identification of the health and economic burden of a condition. A study in South Africa in the late 1980s estimated the costs to the country of smoking, e.g. lost productivity due to premature death and the costs of health care ${ }^{14}$ It found that these and future costs outweighed any economic benefit the industry may have brought to South Africa.

Once the burden has been established, follow-up studies estimate the cost-effectiveness of intervention strategies and sometimes move on to assessments of the affordability of interventions, including scaling up. A well-known instance of the use of CEA to this end in South Africa is the case of ART: CEAs, in tandem with estimates of the economic burden of the disease, built the case for treatment when government appeared resistant. Studies first demonstrated the cost-effectiveness of the prevention of mother-to-child transmission and the introduction of antiretrovirals to the general population, then investigated different options for delivery, and finally estimated the affordability of scaling up. The following are some examples of costeffectiveness studies on ART for HIV/AIDS in South Africa:

Estimates of the health and economic burden of HIV/AIDS. In the early 1990s, a study projected the future health and economic burden of HIV/AIDS. ${ }^{15}$ In 2000, a study projected the impact of HIV/ AIDS on the South African health sector. ${ }^{16}$

Cost-effectiveness analyses of prevention of mother-to-child transmission. It was estimated that a national programme preventing a third of expected paediatric HIV infections would be relatively cheap per capita and in terms of cost-effectiveness would compare well with other public health and clinical interventions in middleincome countries. ${ }^{17}$ It was found that each HIV-positive child costs the South African government more in terms of health care and welfare than to reduce mother-to-child transmission of HIV through the use of nevirapine. ${ }^{18}$

Cost-effectiveness analyses of ART. Building on the projections of studies in the mid- and late 1990s, a detailed cost-effectiveness study confirmed that treatment is cost-effective. ${ }^{2}$ ART leads to overall health service savings as it reduces the need for clinical care; this cost saving increases as drug prices come down. ${ }^{19}$ A KwaZulu-Natal study of the cost of extending ART to health care workers motivated that these costs would be moderate and that benefits would be reduced absenteeism and alleviation of future staff shortages. ${ }^{20}$

Analyses of affordability. Following the introduction of ART in South Africa, the costs and cost-effectiveness of one of the longest-running public antiretroviral programmes in Africa, based in Khayelitsha, Cape Town, were studied. It provided data on the incremental costs and cost-effectiveness associated with scaling up services to assist in decisions around budget development and resource allocation. ${ }^{21}$ Escalating costs as patients move from firstline to second-line treatment and the proportion of unmet need that could be met at different budget levels were subsequently studied using a 'health-maximising' combination of different interventions (no ART, first-line ART and first- and second-line ART). ${ }^{22}$

In the Western Cape perceptions at community, health service and policy level around the introduction of the human papillomavirus vaccine to prevent cervical cancer were studied. ${ }^{23}$ This, and a CEA (not yet published), led the Department of Health to consider introducing the vaccine into its immunisation programme. ${ }^{7}$ The cost-effectiveness study indicates the vaccine price at which it will become cost-effective to introduce the vaccine, which can assist the government in negotiating a reduced vaccine price.

CEA at the population level is also used to suggest alternatives for addressing a broad problem area. A study on the choice of interventions to control air pollutants found that in South Africa the most costeffective interventions are those that focus on the household level, e.g. training people to place firewood on top of, rather than under, the coal in a fireplace and encouraging the insulation of ceilings. ${ }^{24}$ In contrast, government tends to focus on industrial pollutants: these tend to be cost-ineffective interventions.

A study showing the value of re-introducing residual spraying of households to control malaria is influencing practice in African countries that previously focused exclusively on insecticide-treated bed nets. ${ }^{7}$ In Mozambique it was found that residual spraying was relatively inexpensive and reduced malaria-related suffering, including a reduction of malaria rates in neighbouring South Africa. $^{25}$

CEA therefore encourages government to choose explicitly between different courses of action. Such trade-offs are highlighted by a study that considered the costs and affordability of scaling up ART and revealed how extending second-line treatment to patients has reduced the chance of meeting the goal of universal access to first-line treatment. ${ }^{22}$

Internationally, the need to make explicit equity and efficiency trade-offs between different choices, and to incorporate affordability concerns, has led to a third application of CEA analysis in populationlevel priority setting, namely the development of 'packages' of care to define what services the state aspires (or guarantees) to fund and provide to its population (either directly or indirectly through insurance mechanisms and contracted providers). Developing such 'essential health care packages' hinges on, first, identifying health problems that are responsible for the highest burden of disease and, second, identifying highly cost-effective conditions that address these problems. Thus scarce resources are made to go further, significantly impacting on population health.

Under apartheid South Africa did not have good data on the burden of disease, even at the national level and even for mortality. Attempts to provide more reliable estimates of the disease burden of poor and marginalised communities began in the early 1990s and informed policy around the time of the first democratic elections. ${ }^{26}$ Improving the quality of mortality data since the mid-1990s enabled more extensive analyses of mortality data, although problems remain in estimating the burden accurately for certain conditions and communities.

The 2000 national burden of disease study for the first time provided disaggregated data by province. ${ }^{27}$ The Western Cape has 
done a more detailed analysis of the burden of disease within the province. ${ }^{28-29}$ This study prioritised the most important health problems and risk factors and stimulated discussion on priority interventions within the provincial Department of Health. This is perhaps the first example of burden of disease information being channelled into a detailed planning process, especially at the provincial level. The study was especially useful in highlighting neglected areas, such as the importance of motor vehicle accidents in young children, violence against older children, and alcohol abuse (personal communication with sub-district manager in the Western Cape Department of Health).

A more detailed burden of disease exercise identifying the burden associated with key risk factors and suggesting key interventions was conducted in 2007. Key interventions were derived through examining international and local evidence (on cost-effectiveness, among other things) and through consulting with experts. ${ }^{30-44}$ Importantly, these interventions are not simply biomedical in nature, but extend to interventions aimed at health promotion, social change and development. ${ }^{31}$

Given remaining problems with the quality of national mortality data, and difficulties in obtaining disaggregated data on the disease burden faced by poor and marginalised communities, alternative strategies have emerged in South Africa. For example, the Agincourt Health and Demographic Surveillance System, located in a remote rural area in north-eastern South Africa, has provided more detailed and accurate data that deepen, and sometimes overturn, understanding developed on the basis of national datasets (e.g. the TB burden is double the original estimate). ${ }^{45}$

Several South African exercises also inform the other side of package development, namely prioritising interventions that address the main burden of disease. Generally these do not rely heavily on cost-effectiveness information but include an analysis of cost and affordability.

The Need Norms Project assembled a primary care package based on empirical evidence from 'best practice' sites and norms developed through consultation with experts: service targets developed through this process were modified by the application of specific principles, including affordability and cost-effectiveness considerations, especially with respect to targeting and the frequency of interventions. ${ }^{46}$ Modified data from this project were used to develop an official primary health care package for the post-apartheid government. ${ }^{47}$ The package was based on the principles of equity and comprehensiveness and aimed to influence the organisation of services in the direction of patient-centeredness. ${ }^{48}$ It was also affordable, costing less than the actual per capita expenditure on primary care as estimated through a national health accounts exercise. $^{49}$

The primary health care package was followed by the development of packages for district, regional and tertiary hospitals. ${ }^{50-52}$ These mainly arose out of wide-ranging consultation with experts (although the primary and district hospital packages were also informed by empirical costing studies). Presumably cost-effectiveness information would have influenced expert advice, but it was not used as the main instrument for making choices between different components of the package. The same holds true for the legislated 'Prescribed Minimum Benefits' that must be provided by South African medical schemes.

The use of CEA in ranking interventions for inclusion in a government-sanctioned package has limitations. ${ }^{49,53-54}$ For example, studies that compare a range of interventions across the spectrum of health conditions are extremely complex: data and methodological failings can skew findings, while it is difficult to know how to rank interventions that have not yet been researched. Listing individual interventions can also unwittingly encourage verticalisation of programmes. A focus on cost-effectiveness can also detract from dealing with the underlying structural problems that cause inefficiencies and indeed ill-health. In South Africa, these limitations raise concerns about how a package determined on the basis of cost-effectiveness would impact on equity and the achievement of a functional district health system.

Partly for these reasons, the application of essential health packages has had mixed results internationally. ${ }^{49,55}$ To focus on one of the more positive and well-documented examples, the Tanzanian Health Interventions Project was able to bring about a $40 \%$ reduction in mortality in demonstration districts; however, this impact resulted from a range of interventions and not just the application of cost-effectiveness information, and involved considerable technical support at the district level.

\section{Conclusions}

Some capacity to undertake costing and CEA in South Africa already exists. CEA information has already influenced clinical decisionmaking and policy. The following are possibilities offered by CEA and burden of disease estimates to contribute further to decision-making in South Africa:

1. Promotion of dialogue on health and health care priorities as well as affordability.

2. Advocacy against interventions that are clearly cost-ineffective and unaffordable (especially at central hospital level).

3. Advocacy for interventions that strengthen the district health system (because of the highly cost-effective nature of primary and district hospital care), including motivation for increased funding from Treasury.

4. Advocacy for acceptable pricing of drugs and vaccines.

5. Assessment of innovative new interventions, including those for emerging conditions.

6. Identifying clusters of interventions that can enhance the shared use of inputs, reduce costs to patients, achieve synergy between interventions, reach related individuals, and screen patients at the primary level to increase efficiency of referral.

7. Clarification of the roles of different providers and levels of care. In making this contribution, CEA (and burden of disease estimates) must continue to be careful to:

1. Incorporate equity as an up-front concern through strategies such as disaggregating data according to socio-economic groups and gender, clearly identifying gaps in data which make burden of disease and cost-effectiveness estimates unreliable, taking into account societal costs (especially catastrophic expenditure by households) and acknowledging that there may be occasions were equity concerns over-ride cost-effectiveness.

2. Explore interventions, including clustering of services, that reduce fragmentation (and build features that improve quality, encourage trust in the health system and respect patient dignity).

3. Adjust international experience to the local context.

4. Evaluate the impact of cost-effectiveness-based decisions on resource allocation patterns.

International experience shows that priority setting based on cost-effectiveness and burden of disease estimates is essentially a political rather than a technical exercise and therefore 'political and institutional processes need to be engaged..$^{55}$

Apart from these roles for CEA, improving the performance of the health system is only partly about improving technical efficiency. The public health system is under-resourced, there is a shortage 
of skilled staff, and the system suffers from poor management and low staff morale. Furthermore, health care resources are distributed inequitably across the socio-economic gradient. These features may have more to do with the failure of the health system to address health care priorities than inappropriate choices around specific health care interventions.

This paper is based on a longer report that was funded by the Fogarty International Center at the US NIH and the Bill and Melinda Gates Foundation as part of the launch of the PRICELESS SA initiative, August 2009.

\section{References}

1. Muheki C, McIntyre D, Barnes KI. Artemisinin-based combination therapy reduces expenditure on malaria treatment in KwaZulu Natal, South Africa. Trop Med Int Health 2004;9(9):959-966.

Badri M, Cleary S, Maartens G, et al. When to initiate highly active antiretroviral therapy in subSaharan Africa? A South African cost-effectiveness study. Antivir Ther 2006;11(1):63-72.

3. Zikusooka CM, McIntyre D, Barnes KI. Should countries implementing an artemisinin-based combination malaria treatment policy also introduce rapid diagnostic tests? Malar J 2008;7:176

4. Gaziano TA, Steyn K, Cohen DJ, Weinstein MC, Opie LH. Cost-effectiveness analysis of hypertension guidelines in South Africa: absolute risk versus blood pressure level. Circulation 2005;112(23):35693576 .

5. Gaziano TA. The South African Hypertension Guideline 2006 is evidence-based but not cost-effective. S Afr Med J 2006;96(11):1170-1173.

6. Sinanovic E, Floyd K, Dudley L, Azevedo V, Grant R, Maher D. Cost and cost-effectiveness of community-based care for tuberculosis in Cape Town, South Africa. Int J Tuberc Lung Dis 2003;7(9 Suppl 1):S56-62.

7. Doherty J. The Case of the Health Economics Unit in South Africa. Geneva: World Health Organisation, 2009.

8. Hausler HP, Sinanovic E, Kumaranayake L, et al. Costs of measures to control tuberculosis/HIV in Hausler HP, Sinanovic E, Kumaranayake L, et al. Costs of measures to control tuberculosis/HIV in
public primary care facilities in Cape Town, South Africa. Bull World Health Organ 2006;84(7):528536.

9. Taylor B. NICE rationing of specialised health care services for South Africa? S Afr Med J 2008;98(5):368369 .

0. Parrish A, Blockman M. Clinical excellence and the NICEties of value-based priority setting. S Afr Med J 2008;98(10):758-761.

11. Kenyon C, Ford N, Boulle A. When best practice is bad medicine: a new approach to rationing tertiary health services in South Africa. S Afr Med J 2008;98(5):350-356.

12. Jamison D, Alleyne G, Breman J, et al. Disease Control Priorities in Developing Countries. 2nd ed. New York: World Bank and Oxford University Press, 2006.

13. Laxminarayan R, Ashford L. Using Evidence About 'Best Buys' to Advance Global Health. Policy Brief: Disease Control Priorities Project, 2008

14. McIntyre DE, Taylor SP. Economic aspects of smoking in South Africa. S Afr Med J 1989;75(9):432435 .

15. Centre for Health Policy. AIDS in South Africa: The Demographic and Economic Implications. Johannesburg: Centre for Health Policy, University of the Witwatersrand, 1991

16. Johnson S, Soderland N, Kinghorn A, Njobo T. Projected Impacts of the HIV/AIDS Epidemic on the South African Health Sector. Johannesburg: Abt Associates, South African Department of Health and World Bank, 2000

17. Wilkinson D, Floyd K, Gilks CF. National and provincial estimated costs and cost effectiveness of a programme to reduce mother-to-child HIV transmission in South Africa. S Afr Med J 2000;90(8):794798.

18. Skordis J, Nattrass N. Paying to waste lives: the affordability of reducing mother-to-child transmission of HIV in South Africa. J Health Econ 2002;21(3):405-421.

19. Badri M, Maartens G, Mandalia S, et al. Cost-effectiveness of highly active antiretroviral therapy in South Africa. PLoS Med 2006;3(1):e4.

20. Deghaye N, Pawinski RA, Desmond C. Financial and economic costs of scaling up the provision of HAART to HIV-infected health care workers in KwaZulu-Natal. S Afr Med J 2006;96(2):140-143.

21. Cleary SM, McIntyre D, Boulle AM. The cost-effectiveness of antiretroviral treatment in Khayelitsh South Africa - a primary data analysis. Cost Effectiveness and Resource Allocation 2006;4:20.

22. Cleary SM, McIntyre D, Boulle AM. Assessing efficiency and costs of scaling up HIV treatment. AIDS 2008;22 Suppl 1:S35-42.

23. Harries J, Moodley J, Barone MA, Mall S, Sinanovic E. Preparing for HPV vaccination in South Africa: key challenges and opinions. Vaccine 2009;27(1):38-44

24. Leiman A, Standish B, Boting A, van Zyl H. Reducing the healthcare costs of urban air pollution: the South African experience. J Environ Manage 2007;84(1):27-37.

25. Conteh L, Sharp BL, Streat E, Barreto A, Konar S. The cost and cost-effectiveness of malaria vector control by residual insecticide house-spraying in southern Mozambique: a rural and urban analysis. Trop Med Int Health 2004;9(1):125-132.

26. Bourne D. Analysis of mortality data for 1990. Unpublished report prepared for the Health Expenditure Review, 1994.

27. Bradshaw D, Nanna N, Laubscher R, et al. South African National Burden of Disease Study 2000: estimates of provincial mortality. Cape Town: Burden of Disease Research Unit, Medical Research Council, date unknown.

28. Myers J, Naledi T. Volume 1 of 7: Overview of the Report. Cape Town: Western Cape Department of Health, 2007.

29. Corrigall J, Pienaar D, Matzopoulos R, et al. Executive Summaries of Volumes 2 - 7. Cape Town: Western Cape Department of Health, 2007

30. Bradshaw D, Norman R, Pieterse D, Levitt NS. Estimating the burden of disease attributable to diabetes in South Africa in 2000. S Afr Med J 2007;97(8 Pt 2):700-706.

31. Bradshaw D, Norman R, Lewin S, et al. Strengthening public health in South Africa: building a stronger evidence base for improving the health of the nation. S Afr Med J 2007;97(8 Pt 2):643-649.

32. Groenewald P, Vos T, Norman R, et al. Estimating the burden of disease attributable to smoking in South Africa in 2000. S Afr Med J 2007;97(8 Pt 2):674-681.

33. Lewin S, Norman R, Nannan N, Thomas E, Bradshaw D. Estimating the burden of disease attributable to unsafe water and lack of sanitation and hygiene in South Africa in 2000. S Afr Med J 2007:97(8 Pt 2):755-762
34. Nannan N, Norman R, Hendricks M, Dhansay MA, Bradshaw D. Estimating the burden of disease attributable to childhood and maternal undernutrition in South Africa in 2000. S Afr Med J 2007;97(8 Pt 2):733-739.

35. Nojilana B, Norman R, Bradshaw D, van Stuijvenberg ME, Dhansay MA, Labadorios D. Estimating the Nojilana B, Norman R, Bradshaw D, van Stuijvenberg ME, Dhansay MA, Labadorios D. Estimating the
burden of disease attributable to vitamin A deficiency in South Africa in 2000. S Afr Med J 2007;97(8 Pt 2):748-753.

36. Nojilana B, Norman R, Dhansay MA, Labadarios D, van Stuijvenberg ME, Bradshaw D. Estimating the burden of disease attributable to iron deficiency anaemia in South Africa in 2000. S Afr Med 2007;97(8 Pt 2):741-746

37. Norman R, Barnes B, Mathee A, Bradshaw D. Estimating the burden of disease attributable to indoor air pollution from household use of solid fuels in South Africa in 2000. S Afr Med J 2007;97(8 P 2):764-771

38. Norman R, Bradshaw D, Schneider M, et al. Estimating the burden of disease attributable to interpersonal violence in South Africa in 2000. S Afr Med J 2007;97(8 Pt 2):653-656.

39. Norman R, Bradshaw D, Steyn K, Gaziano T. Estimating the burden of disease attributable to high cholesterol in South Africa in 2000. S Afr Med J 2007;97(8 Pt 2):708-715.

40. Norman R, Cairncross E, Witi J, Bradshaw D. Estimating the burden of disease attributable to urban outdoor air pollution in South Africa in 2000. S Afr Med J 2007;97(8 Pt 2):782-790.

41. Norman R, Gaziano T, Laubscher R, Steyn K, Bradshaw D. Estimating the burden of disease attributable Norman R, Gaziano T, Laubscher R, Steyn K, Bradshaw D. Estimating the burden of dises
to high blood pressure in South Africa in 2000. S Afr Med J 2007;97(8 Pt 2):692-698.

42. Norman R, Mathee A, Barnes B, van der Merwe L, Bradshaw D. Estimating the burden of disease attributable to lead exposure in South Africa in 2000. S Afr Med J 2007;97(8 Pt 2):773-780.

3. Schneider M, Norman R, Parry C, Bradshaw D, Pluddemann A. Estimating the burden of disease attributable to alcohol use in South Africa in 2000. S Afr Med J 2007;97(8 Pt 2):664-672.

4. Schneider M, Norman R, Steyn N, Bradshaw D. Estimating the burden of disease attributable to low fruit and vegetable intake in South Africa in 2000. S Afr Med J 2007;97(8 Pt 2):717-723.

45. Tollman S, Kahn K, eds. Health, population and social transitions in rural South Africa. Scand J Public Health 2007;35(suppl 69):4-187.

46. Rispel L, Price M, Cabral J. Confronting Need and Affordability: Guidelines for Primary Health Care Services in South Africa. Johannesburg: Centre for Health Policy, 1996.

47. Department of Health. The Primary Health Care Package for South Africa - a set of norms and standards. Pretoria: Department of Health2000.

48. Daviaud E, ed. To what extent and in what conditions does a core package of PHC services contribute to the pursuit of equity? (conference paper). The Attainability and Affordability of Equity in Health Care Provision, 28 June - 25 July 1997, The Phillippines.

49. Doherty J, Govender R. The cost-effectiveness of primary care services in developing countries: review of the international literature. Washington: World Bank, World Health Organization, Fogarty International Centre of the US National Institutes of Health, 2004.

50. Department of Health. A District Hospital Service Package for South Africa: A Set of Norms and Standards. Pretoria: Department of Health, 2002.

1. National Department of Health. A Regional Hospital Service Package for South Africa. A Draft Proposal. Pretoria: National Department of Health, 2002 .

52. National Department of Health. Modernisation of Tertiary Services Project (MTS): National Plan for the Efficient and Equitable Development of Tertiary and Regional Hospital Services. Pretoria: National Department of Health, 2009 .

53. Doherty J. Basic packages: origin, rationale and costs. Health service delivery in fragile states for $\$ 5 \mathrm{per}$ person per year: myth or reality? Conference co-hosted by Merlin and the London School of Hygiene and Tropical Medicine, 24 - 25 October 2007, London.

54. Alvarez-Castillo F, Ravindran S, de Pinho H. Priority setting. In: Ravindran S, de Pinho H, eds. The Right Reforms?: Health Sector Reform and Sexual and Reproductive Health. Johannesburg: Women's Right Reforms?: Health Sector Reform and Sexual and

55. World Health Organization. Essential Health Packages: What Are They For? What Do They Change? Technical Brief No. 2. Geneva: World Health Organisation, 2008.

56. Lundkvist J, Kastang F, Kobelt G. The burden of rheumatoid arthritis and access to treatment: health burden and costs. Eur J Health Econ 2008;8(Suppl 2):S49-60.

7. Novitzky N, Mobara G, Jacobs P. Antilymphocyte globulin and high-dose methylprednisolon improve survival in patients with aplastic anaemia without additional financial costs. S Afr Med J 1992;81(5):254-257.

5. Hussey GD, Lasser ML, Reekie WD. The costs and benefits of a vaccination programme for Haemophilus influenzae type B disease. S Afr Med J 1995;85(1):20-25

59. Pestana JA, Steyn K, Leiman A, Hartzenberg GM. The direct and indirect costs of cardiovascular disease in South Africa in 1991. S Afr Med J 1996;86(6):679-684.

60. Lund C, Boyce G, Flisher AJ, Kafaar Z, Dawes A. Scaling up child and adolescent mental health services in South Africa: Human resource requirements and costs. J Child Psychol Psychiatry 2009;50(9):11211130.

61. Sayed AR, Bourne D, Pattinson R, Nixon J, Henderson B. Decline in the prevalence of neural tube defects following folic acid fortification and its cost-benefit in South Africa. Birth Defects Res A Clin Mol Teratol 2008;82(4):211-216.

62. Kevany S, Meintjes G, Rebe K, Maartens G, Cleary S. Clinical and financial burdens of secondary level care in a public sector antiretroviral roll-out setting (G F Jooste Hospital). S Afr Med J 2009;99(5):320325 .

63. Dyer JJ. Comparative costs of mobile and fixed-clinic primary health care services. S Afr Med J 1996;86(5):528-530

64. Goodman CA, Mnzava AE, Dlamini SS, Sharp BL, Mthembu DJ, Gumede JK. Comparison of the cos and cost-effectiveness of insecticide-treated bednets and residual house-spraying in KwaZulu-Natal, South Africa. Trop Med Int Health 2001;6(4):280-295

65. Boulle A, Kenyon C, Skordis J, Wood R. Exploring the costs of a limited public sector antiretroviral treatment programme in South Africa. S Afr Med J 2002;92(10):811-817.

66. Wilkins JJ, Folb PI, Valentine N, Barnes KI. An economic comparison of chloroquine and sulfadoxinepyrimethamine as first-line treatment for malaria in South Africa: development of a model for estimating recurrent direct costs. Trans R Soc Trop Med Hyg 2002;96(1):85-90.

67. Wilkinson D, Floyd K, Gilks CF. Costs and cost-effectiveness of alternative tuberculosis management strategies in South Africa - implications for policy. S Afr Med J 1997:87(4):451-455.

68. Goldhaber-Fiebert ID, Denny LE, De Souza M, Wright TC, Jr., Kuhn L, Goldie SJ. The costs of reducing loss to follow-up in South African cervical cancer screening. Cost Effectiveness and Resour ce Allocation 2005;3:11.

69. Sinanovic E, Kumaranayake L. Financing and cost-effectiveness analysis of public-private partnerships provision of tuberculosis treatment in South Africa. Cost Effectiveness and Resource Allocation 2006;4:11.

70. Rosen S, Long L, Sanne I. The outcomes and outpatient costs of different models of antiretroviral treatment delivery in South Africa. Trop Med Int Health 2008 Aug;13(8):1005-1015.

71. Vijayaraghavan A, Efrusy M, Lindeque G, Dreyer G, Santas C. Cost effectiveness of high-risk HPY DNA testing for cervical cancer screening in South Africa. Gynecol Oncol 2009;112(2):377-383.

Accepted 19 August 2010 
Appendix A. South African studies that look at the burden of disease and costs and benefits of interventions

\begin{tabular}{|c|c|}
\hline Category & Main findings and policy relevance \\
\hline Assessment of the burden of disease & $\begin{array}{l}\text { - Analyses of mortality data have been conducted since the early } 1990 \text { s. There have been } \\
\text { some improvements in the quality of mortality data over this time, but studies still have } \\
\text { to make extensive extrapolations based on demographic and epidemiological models. } \\
\text { The most recent national burden of disease study was able, for the first time, to provide } \\
\text { disaggregated data by province, as a first step in illuminating the inequalities that } \\
\text { characterise South African society. The study found that all provinces face a 'quadruple' } \\
\text { burden of disease (that is, diseases associated with poverty, non-communicable illness, } \\
\text { injuries and HIV/AIDS). }{ }^{27} \\
\text { - The Western Cape conducted its own, more detailed burden of disease study in } 2007 \text {. }^{28-29} \\
\text { This study prioritised the most important health problems and risk factors and began a } \\
\text { process of identifying priority interventions to address these problems. } \\
\text { - In } 2007 \text {, a study estimated the burden of disease in South Africa resulting from major risk } \\
\text { factors. It identified the priority factors that need to be addressed and suggested a range of } \\
\text { interventions based on international and local studies. }{ }^{30-44} \\
\text { - A recent international study estimated the health and economic burden of rheumatoid } \\
\text { arthritis in several countries, including South Africa. }{ }^{56}\end{array}$ \\
\hline $\begin{array}{l}\text { Assessment of when it is cost-effective for an } \\
\text { individual patient to receive an intervention }\end{array}$ & $\begin{array}{l}\text { - An early study found that, in selected patients with aplastic anaemia who do not have the } \\
\text { option of receiving an allogeneic bone marrow transplant, it is cost-effective to provide } \\
\text { treatment with antilymphocyte globulin combined with high-dose methylprednisolone. }{ }^{57} \\
\text { - A study assessed whether South African hypertension guidelines are cost-effective. It found } \\
\text { that the strategy at that time of deciding on treatment based on a target blood pressure level } \\
\text { (i.e. a single risk factor) was more costly and less effective than initiating treatment based } \\
\text { on an estimation of global risk (due to a number of factors) of more than } 15 \% \text {. The study } \\
\text { concluded that the use of the latter approach would free up substantial resources. }{ }^{4} \\
\text { - Work has been done with respect to the CD4 count at which patients should receive ART, } \\
\text { suggesting that initiating treatment before the CD4 counts fall to } 200 \text { is more cost-effective. }\end{array}$ \\
\hline $\begin{array}{l}\text { Assessment of whether an intervention for an } \\
\text { emerging condition is sufficiently cost-effective } \\
\text { to warrant a government programme }\end{array}$ & 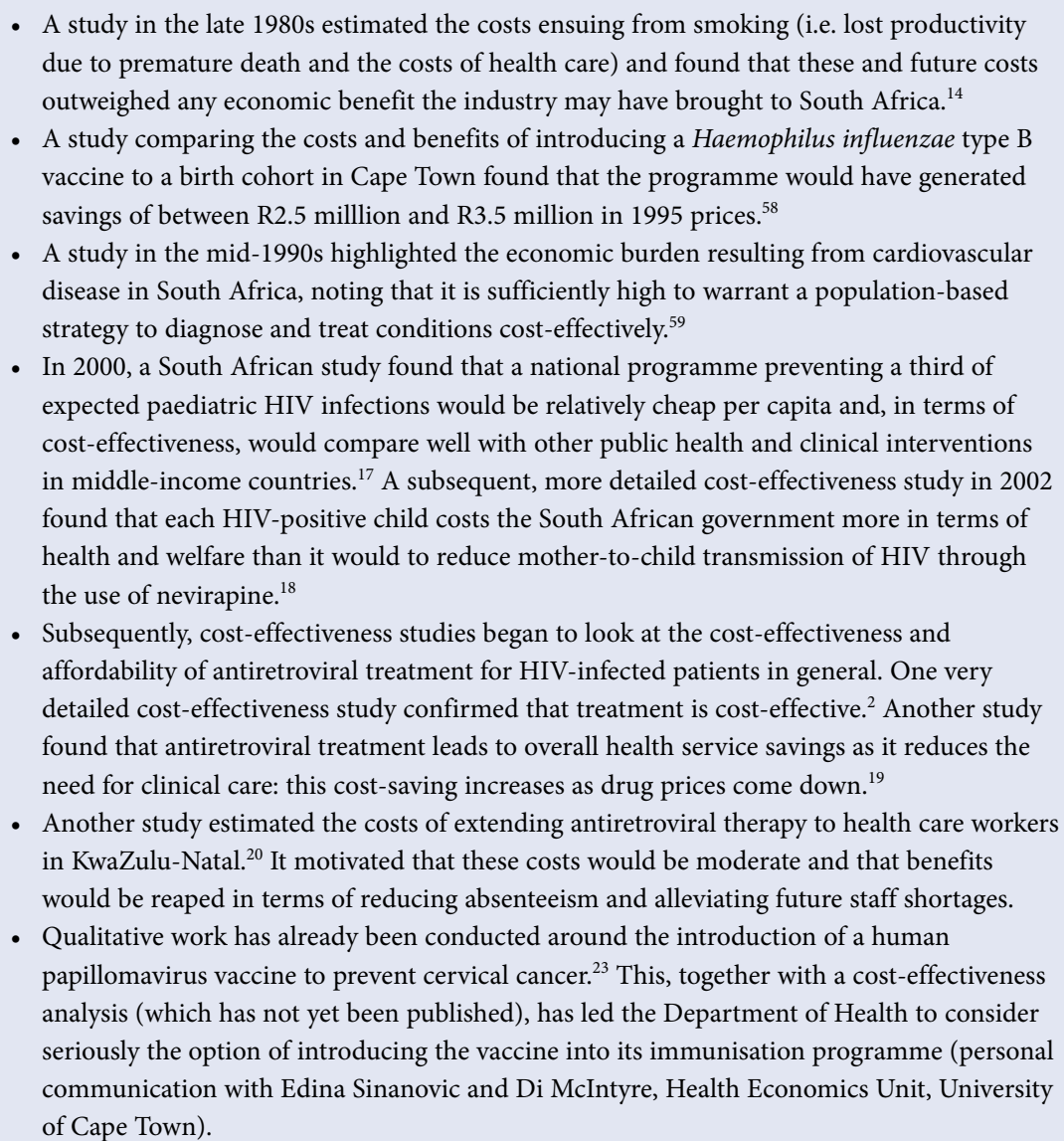 \\
\hline
\end{tabular}


Assessment of the affordability of scaling up an intervention

Evaluation of interventions

Comparison of alternative interventions or different models of delivery
- A tool was developed to assess resource requirements for scaling up mental health services for children and adolescents, at different levels of coverage. ${ }^{60}$ The study showed a substantial shortfall in current services.

- The study described above on the introduction of a human papillomavirus vaccine to prevent cervical cancer, also indicates the vaccine price at which it will become cost-effective to introduce the vaccine. This can assist the government in negotiating a reduction in the price of the vaccine (personal communication with Di McIntyre, Health Economics Unit, University of Cape Town).

- In 2003 South Africa initiated a programme to fortify staple foods with folic acid. A subsequent study found a decline of around a third in neural tube defects in new births. The study estimated that the medical intervention costs that were averted by folic acid supplementation amounted to 30 times the cost of the supplementation programme. ${ }^{61}$

- A study looking at the costs of treating patients in secondary hospitals around the time of antiretroviral initiation showed that the burden on these hospitals was significant, resulting in the need for government to accommodate these costs in its plans. ${ }^{62}$

- The costs and benefits of mobile versus fixed-clinic services were analysed to assist in improving the efficiency of primary health care. ${ }^{63}$

- A study compared the cost-effectiveness of residual house-spraying versus insecticide-treated bed nets in the control of malaria in KwaZulu-Natal. It found bed nets to be more cost-effective, despite their higher costs, but cautioned that close monitoring of the use of nets was necessary to assess if cost-effectiveness would change over time. ${ }^{64}$

- An early study looking at ART provision explored different scenarios for delivering treatment and suggested that treatment could be cost-effective and affordable, depending on different policy choices. ${ }^{65}$

- A study found that although a course of sulfadoxine-pyrimethamine is much more expensive than chloroquine for malaria treatment, it is almost 5 times more cost-effective. ${ }^{66} \mathrm{~A}$ subsequent study found that replacing monotherapy (with sulphadoxine-pyrimethamine) with dual therapy (i.e. artemether-lumefantrine) in KwaZulu-Natal led to a decline of around a third and half of the outpatient cases and inpatient admissions, respectively. ${ }^{1}$ Although dual therapy is considerably more expensive, its better cure rate led to a saving of around \$200 000 in 2002 alone. However, this was in a context of low efficacy of monotherapy and good vector control.

- In 1997, an economic analysis of community-based directly observed therapy for tuberculosis in Hlabisa, KwaZulu-Natal, found that costs to both patients and the health service were reduced considerably by using community observation. ${ }^{67}$ This form of care was also cost-effective. A subsequent study that looked at outcomes and costs of TB treatment in Cape Town compared clinic-based care with clinic-based care supported by observation by community health workers. The study, which included costs from a societal perspective, found that community involvement improved the affordability and cost-effectiveness of treatment. ${ }^{6}$ Another study noted that community health workers increase the return rate of women who miss their scheduled visits for cervical screening and that these benefits should be incorporated in future cost-effectiveness analyses aimed at policy decisions about cervical cancer screening. ${ }^{68}$

- Another study found that there is a strong economic case for expanding public-private partnerships in TB treatment, concluding that, if these partnerships are tailored to target groups and supported by the public sector, scaling up would be much more affordable than public models of delivery (partly because some of these partnerships are work-based and thus close to the patient). ${ }^{69}$

- A cost-effectiveness study found that the 'ProTEST package' of combined TB and HIV interventions in the primary care setting in Cape Town was cost-saving. ${ }^{8}$ The prevention of TB cost less than previous estimates because of the linkage of prevention and care interventions for both TB and HIV. Voluntary counselling and testing was also found to be less expensive than reported in other African studies.

- A study comparing the costs and benefits of different interventions to control air pollutants found that the most cost-effective interventions are those that focus on the household level..$^{24} \mathrm{By}$ way of contrast, government focuses on industrial pollutants, with most proposed industrial interventions failing the cost-benefit test. Household interventions include lowcost interventions such as training householders to place firewood on top of the coal in a fireplace and encouraging the insulation of ceilings. The control of pollution from vehicle fuels was the next most important set of interventions.

- A study investigated the different outcomes and costs of different models for antiretroviral delivery. The models were an urban public hospital, a programme that contracts private general practitioners, a rural non-governmental AIDS clinic, and a peri-urban nongovernmental primary care clinic. ${ }^{70}$

- A study that determined the cost-effectiveness of cervical cancer screening strategies that involved human papillomavirus testing found that testing is cost-effective. ${ }^{71}$ The study presented the incremental costs of different combinations of screening strategies. 